\title{
Socio-Cultural Values Influences on the Housing Design towards Sustainable Community in the Gaza Strip
}

\author{
Abdalrahim M. A. Shehab, Mohd Zin Kandar
}

To Link this Article: http://dx.doi.org/10.6007/IJARBSS/v11-i10/11133

DOI:10.6007/IJARBSS/v11-i10/11133

Received: 06 August 2021, Revised: 02 September 2021, Accepted: 27 September 2021

Published Online: 04 October 2021

In-Text Citation: (Shehab \& Kandar, 2021)

To Cite this Article: Shehab, A. M. A., \& Kandar, M. Z. (2021). Socio-Cultural Values Influences on the Housing Design towards Sustainable Community in the Gaza Strip. International Journal of Academic Research in Business and Social Sciences, 11(10), 452-464.

\section{Copyright: @ 2021 The Author(s)}

Published by Human Resource Management Academic Research Society (www.hrmars.com)

This article is published under the Creative Commons Attribution (CC BY 4.0) license. Anyone may reproduce, distribute, translate and create derivative works of this article (for both commercial and non-commercial purposes), subject to full attribution to the original publication and authors. The full terms of this license may be seen at: http://creativecommons.org/licences/by/4.0/legalcode

\section{Vol. 11, No. 10, 2021, Pg. 452 - 464}

Full Terms \& Conditions of access and use can be found at http://hrmars.com/index.php/pages/detail/publication-ethics 


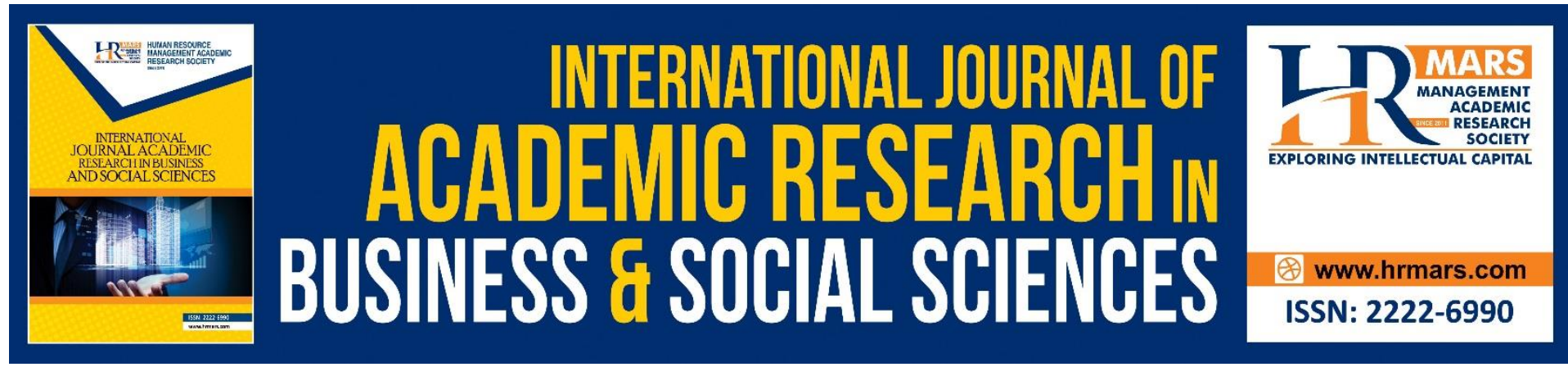

\title{
Socio-Cultural Values Influences on the Housing Design towards Sustainable Community in the Gaza Strip
}

\author{
Abdalrahim M. A. Shehab, Assoc. Prof. Dr Mohd Zin Kandar \\ Faculty of Engineering and Build Environment, Universiti Sains Islam Malaysia, Bandar Baru \\ Nilai, 71800, Nilai, Negeri Sembilan, Malaysia
}

\begin{abstract}
This study highlighted the interrelationships that exist among the significant social factors and cultural factors that influence sustainable housing design. Furthermore, sustainable housing design is a vital area in the built environment literature that consist of social, cultural and economic factors. However, literature revealed that problem of sustainable housing design exists due to the imbalance between these influential factors. This study employed quantitative method design to answer research questions and objectives. Firstly, research investigated the direct relationship between socio-cultural values on sustainable housing design in the Gaza strip. Secondly, the research addressed the antecedents of sustainable housing design (SHD) such as family structure (FS), family values (FV), family lifestyle (FLS), privacy (PV), religion and attitude beliefs (RB), safety and security (SS), in explaining SHD and bridged identified gaps in literature. Therefore, current research design in this research study, self- administered survey was applied. Stratified probability sampling was employed to choose the respondents for quantitative. Survey questionnaires were distributed among 384 residents of Gaza. Data of 252 respondents were analyzed through SEM technique using AMOS 22. Quantitative brings important findings based on socio-cultural factors influencing sustainable housing design. The results revealed that both social factors i.e., family structure (FS), family values (FV), family lifestyle (FLS) and cultural factors i.e., privacy (PV), religion beliefs (RB), safety and security (SS) related positively with sustainable housing design (SHD). The findings have revealed that major themes of both social and cultural factors explaining sustainable housing design (SHD). Overall, findings provide comprehensive constructive insight to employ a sustainable housing design framework align with socio-cultural values in Gaza. Finally, future research should use other forms of analysis based on observation etc. and conduct comparative analysis in context of other Arab countries.
\end{abstract}

Keywords: Socio-Cultural Values, Housing Design, Sustainable Community, Gaza, Palestine.

\section{Introduction}

The idea of housing has remarkably developed. The old human had built their houses only for sheltering purposes. It is the primary need of humans (Mills and Ota, 1989). It is an investment for the long term which gives privacy and security to reach the stability of families (Opoku \& Abdul-Muhmin, 2010). According to Rapoport (1969), home development is an outcome of 
several socio-cultural variables, rather than just physical forces or a single causative cause. Overall, housing is a collection of physical and social systems which come together to form the housing system (Francescato et al., 1987).

The bad situation that the Gaza strip has been living in is due to the Israeli occupation, the shaky situation in terms of politics that created economic, social, and environmental issues. The Israeli occupation military has been performing various strikes resulting in massive destruction. The statistics show that nearly $27 \%$ of the houses in Gaza were heavily damaged in 2014. According to the Palestinian national recuperation and the plan of reconstruction for Gaza, roughly 10,000 dwelling units were destroyed, another 10,000 were severely damaged, and another 40,000 were partially destroyed. These figures are significant in contrast to the overall number of families in the area (about 220,000), implying that around 60,000 households have become homeless. Therefore, immediately after its creation, one of the primary difficulties facing the Palestinian National Authority "PNA" has been to supply additional housing units for its citizens. The need for high-rise structures stems from a desire to fulfill the increasing demand for homes (Asfour, 2012).

Because of their socio-cultural beliefs, most of Gazans still choose to live in detached houses rather than multi-story buildings. According to Ammar (2014), the PNA's decision to develop multi-story residential structures has been influenced by several issues, including the high cost and availability of land, a growing population, and the desire to minimize land usage pressure and vertical lifts invention. Likewise, house design is influenced by socio-cultural ideals. According to Asfour (2012), for any housing requirement to be effectively addressed, the housing project's goal must go beyond simply providing housing units to creating buildings that meet the different demands of possible occupants (in this situation, the Gaza residents), for example, their social and cultural requirements. Creating a housing strategy for the Gaza Strip that involves long-term housing sustainability will most likely necessitate a qualitative framework and operational sustainability (llesanmi, 2010). As a result, the objective of the study is to determine how the Gaza Strip housing environment may be made more sustainable by including Gaza residents' social and cultural demands. The relevance of housing in achieving sustainability has been given a major role. A house can be seen as a family unit that highlights three components of a living: the advancement of economy, social prosperity, and environmental preservation (Almansuri et al., 2009).

\section{Problem Statement}

Asfour (2012) has observed that cultural and social principles, as well as economic factors, are equally significant. There is a strong link between cultural and social characteristics as well as the household socioeconomic level and urban sustainability since these variables have a greater impact on urban space sustainability (Tavassoli \& Fathi, 2013). Even though some of these elements are moral, it is dangerous to isolate them from the housing environment especially in the Palestinian context where culture and social norms have firmly ingrained the demand for sustainable housing to suit the requirements of Gaza inhabitants. As a result, this research is concerned with bridging the gap and investigating the link between cultural and social factors and the home design of Gaza Strip to achieve community sustainability.

\section{Objective of the Study}

The primary objective in this research is to look at the impact of conventions of culture and society on sustainable housing design in Gaza strip as well as build a framework based on social and cultural principles as well as sustainable housing design 


\section{Significance of the Study}

Designing a sustainable house is no longer luxurious; it is now critical to the current generation's and future generations' existence (Hamed, 2003). Similarly, culture, nature, and the environment of the inhabitants are essential factors to consider when it comes to creating homes and environments for human beings (Ani et al., 2012). As a result, cultural, social, environmental, and economic aspects must all be considered in the context of sustainable housing design to provide pleasant houses that will increase the residents' quality of life (Ghaffarian Hoseini et al., 2013). People's socio-cultural principles have a critical part in establishing the identity and the character of any building, and they must be included in any successful housing design (Edwards \& Roelofs, 2006).

\section{Literature Review}

Various scholars define housing and sustainability in the literature. It may be characterized as a large, long-lasting, and permanent product that is only created and used in the location where it is constructed. Housing is the most basic socio-economic condition that determines a society's quality and well-being (Un-Habitat, 2004). It performs a more powerful impact on universal and societal peace than other structures. It is a concept of acceptable housing that includes activities that are both environmentally friendly and socially responsible (Edwards, 2000). While striving to lessen the negative impact of housing on the environment by utilizing environmentally friendly infrastructure and design (Gilkinson \& Sexton, 2007). Much research has been undertaken to clarify housing concepts. Housing and sustainability, according to the researchers, can coexist inexorably.

\section{Relationship between Socio-cultural Values and Housing Design}

Housing design is linked to the neighborhood's social order and the facilitation of network connections and social status among the residents. Community sustainability refers to a community's skill or performance of being able to maintain and imitate at suitable levels of effort. It is linked to the concepts of "social solidarity" and "social capital" which encompass reciprocal norms, social networks, and social organization features, as well as the integration of the resultant social behavior (Dempsey, 2008). Because it assures the maintenance or enhancement of the well-being of present and future generations, social and cultural sustainability is reciprocal and tightly connected.

According to Jiboye (2010), there is a strong link between social and cultural aspects in home living and sustainability. It indicates that paying attention to human requirements while designing houses improves the environment quality. The findings show that cultural and social elements have a major impact on long-term sustainability. Researchers' study findings on sustainable housing supply for the urban poor have been used as a way to measure life quality (Tavassoli \& Fathi, 2013). Furthermore, Alahmed (2014) discovered that social preconditions favorable to housing provision are essential for sustainable housing and, as a result, a livable environment.

\section{Conceptual Framework and Study Hypothesis}

Theoretical Perspective depicted in 1.1 illustrates how the link between the six categories of socio-cultural elements that influence citizen contentment is seen in broad terms. 


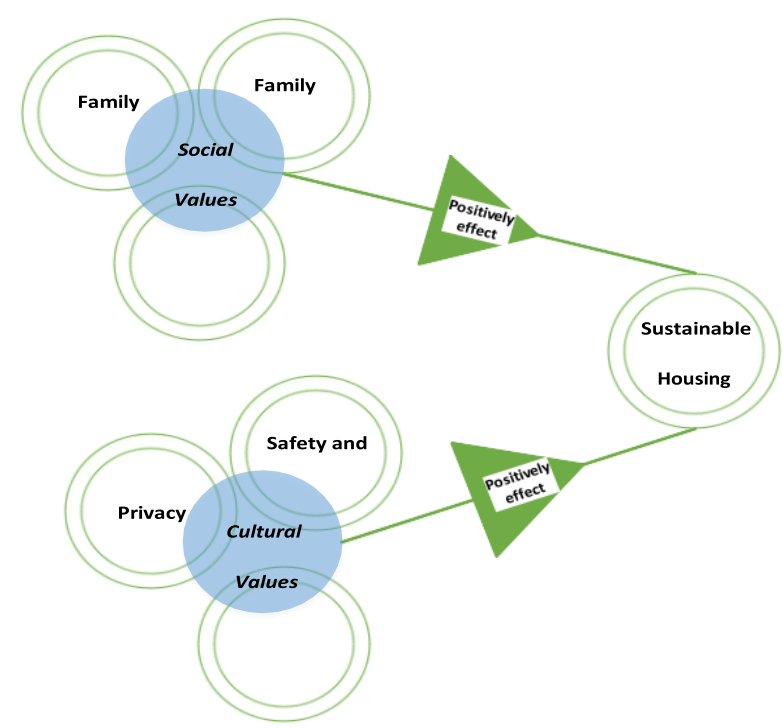

Figure1.1: The Conceptual Framework

\section{Housing Design}

Housing is a residential setting that offers equipment, the physical structure, amenities, shelter, and gadgets that are necessary for social well-being to its residents. Housing is important to a city's sustainable viability. Developing economies and rural areas, on the other hand, receive less attention (Varol et al., 2011). Many variables influence the sustainability of housing designs in Gaza. Nevertheless, economic concerns, social and cultural values are both essential to consider (Asfour, 2012).

\section{Social Values}

Family structure, family values, and family lifestyle all influence social values. The following variables work in tandem and are described more below:

\section{Family Structure}

Family structure develops from a socio-culture overall that is either collectivist or individualistic. Individualism usually promotes a self-contained family system, whereas collectivism promotes an interconnected family system. As a result, houses are constructed according to the kind of family structure. Most eastern nations, on the other hand, continue to boost the ideas of their society and culture by their interdependent structure of the family, and have structured their homes to imitate those principles in the family structure (Ozaki, 2002).

\section{Family Lifestyle}

Various studies have already found the influence of house design on future residents' lifestyles and physical quality of life, indicating ecologically sound measures throughout the construction process.

\section{Family Values}

In most cases, family values are created in reaction to a community's cultural and social propensity toward independence or interdependence. Interdependence is characterized by 
increased emotional dependency among individuals in society, whereas independence is characterized by member's self-reliance. Individuals are transformed as independent or dependent as a result of their parenting and early socialization. Although social housing has been widely researched, this legislation has had little influence when compared to home design values (Kowaltowski \& Granja, 2011).

\section{Culture Values}

Religious values, privacy, and security, and safety are examples of cultural factors that determine societal aspects. The following elements complement one another and are described more below:

\section{Religious Perceptions and Assumptions}

According to Alaghbari (2010), social and cultural variables are important when it comes to family size and Islamic-based family practices, such as those relating to privacy and women who seem to be invisible, which have a key role in the construction of sustainable housing. Additionally, cultural and social activities are not overlooked in the design of housing, resulting in the establishment of such a solution. Religious attitudes and ideas are held in high respect as a tradition. As an alternative to public parks, parks for relative families have been built in every place, where socio-cultural or religious reasons do not justify the free interaction between men and women. Foreigners are not permitted to utilize these gardens; only those who are authorized to communicate in this community are permitted to do so (Horn \& Skomsvold, 2011).

\section{Privacy}

The significance of privacy in housing design cannot be overstated. This component of culture is linked to Islamic religious traditions widely practiced in Gaza (Jabareen, 2005). The religious, social, and legal foundations of Islam forbid violations of one's privacy and provide the threshold that separates the public from the private a symbolic meaning. i.e., the front door. Ozaki (2002) surveyed the residents of a new housing prototype. The study revealed that the new house prototype had no privacy. The new home prototype's tenants in Gaza are concerned about the lack of privacy, both auditory and visual. Jiboye (2004) discovered that demographic characteristics have an impact on where people live. Housing features such as the number of bedrooms, bedroom sizes, level of privacy, and overall house size have all been explored by past researchers.

\section{Security and Safety}

Kowaltowski \& Granja looked into housing standards, a sense of security in the neighborhood, and the physical components of the home and its surroundings (2011). Housing conditions have a direct impact on social situations. As a result, well-designed sustainable housing can equip homeowners with the favorable social conditions required for healthy community growth. When a house is judged socially acceptable, it immediately meets the cultural needs of people in terms of budget, size, and function (Salama, 2006, Sidawi, 2008). In the same way, a culturally acceptable house design incorporates intangible benefits such as security, safety, aesthetics, and a sense of personal and societal progress (Friedman, 2005). As a result, housing project planning and design must look beyond economic considerations to incorporate this vital cultural dimension of resident safety and security (Makinde, 2015). 


\section{Sustainable Community}

Sustainable communities are new frontiers to be explored, locations that have been designed and developed to address a variety of social, economic, and environmental concerns. Eventually, if these freshly built neighborhoods are to become true sustainable communities, several impediments to pro-environmental behavior must be removed (Duxbury \& Jeannotte, 2011). To set the stage, it's vital to highlight that both research and practices related to cultural inclusion in sustainability are new and diverse. In material from Australia, it is clear that policy attention and thinking regarding culture and sustainable communities is growing (Duxbury, 2007).

\section{Methodology}

The objectives of this study have been accomplished using an explanatory research design and quantitative research. The quantitative study section includes closed-ended data on the variables FS, FV, FLS, PV, RB, SS, and SHD. Quantitative research is typically connected with a logical technique in which a theory is verified by adding facts and numbers, according to Greener (2008). As a result, positivist and objectivist perspectives are more prevalent. Quantitative research, on the other hand, is described as the examination of the relationship between variables in order to test objective theories. (2013, Creswell). The link between these factors can be investigated in quantitative research using numerical data and statistical tools and methodologies. A survey-based research design, on the other hand, examines a sample of the population to provide such a statistical or mathematical interpretation of population trends, behaviors, or opinions (Creswell, 2013). To achieve the research aims, this study uses 252 samples. They therefore appear to be a representative sample of the population (Krejcie \& Morgan, 1970). The validity, analysis, convergent validity, discriminant validity, and reliability of the measurement model are all evaluated based on criteria that are typically compatible with the data.

\section{Data Collection}

For quantitative data collecting, the quantitative technique employs random probability sampling to select respondents. 384 inhabitants of Gaza's five largest cities have been given survey questionnaires. Around 284 surveys have been collected, with a response rate of around $74 \%$. Clean data comprising 252 respondents have been examined using the structural equation modeling (SEM) technique in AMOS 22 after missing values, normality, and outliers have been checked.

\section{Analysis and Result}

SEM has been utilized in this paper. AMOS 22 has been used to do path analysis between independent and dependent factors. For statistical data analysis, both measurement and structural models have been explored to tackle the research questions and objectives. The measurement model has been validated in first step; the hypotheses have been examined in the second stage using a structural model.

\section{Convergent Validity}

This demonstrates that all of the constructs have sufficient scores to support convergent validity. The AVE values are in the range of 0.551 to 0.820 . After evaluating confirmatory factor analysis (CFA) assessed with AMOS 22, the standardized factor loadings of each variable have been analyzed to estimate the construct's reliability. The construct reliabilities have 
likewise been extracted using the MS Excel macro tool, as has the case with AVE. The construct reliability value for each proposed variable is shown in Table 1.1. The construct reliability standard threshold value has been set at 0.70 or above (Cooper \& Schindler, 2011; Rasli, 2006). It also shows that each variable has sufficient construct reliability, which ranges from 0.786 to 0.887 . As a result, there has been no violation of either variable's convergent validity in this study. Table 1.2 shows the relationship between variables and the square root of AVE values. The findings reveal that all variables have adequate discriminant validity, which means that the mentioned square root of AVE values are more than the inter-construct correlation of each variable, and the inter-construct correlation values are less than 0.80 . As a result, the data give definite evidence of construct discriminant validity.

Table 1.1: $\quad$ Convergent Validity

\begin{tabular}{|l|l|l|l|l|}
\hline Constructs & Items & $\begin{array}{l}\text { Factor } \\
\text { Loading }\end{array}$ & CR & AVE \\
\hline Family Structure & FS04 & FS03 0.742 & & \\
& FS02 & 0.794 & 0.857 & 0.599 \\
& FS01 & 0.783 & & \\
& & 0.777 & & \\
\hline Family Life Style & FLS03 & 0.778 & 0.848 & 0.651 \\
& FLS02 & 0.858 & & \\
& FLS03 & 0.782 & & \\
\hline Family Values & FV03 & 0.742 & 0.786 & 0.551 \\
& FV02 FV010.785 & & \\
& & 0.698 & & \\
\hline Privacy & PV03 & 0.771 & 0.846 & 0.647 \\
& PV02 & 0.835 & & \\
& PV01 & 0.805 & & \\
\hline Religion and & RB03 RB02 & 0.820 & 0.832 & 0.625 \\
Beliefs & RB01 & 0.854 & & \\
& & 0.687 & & \\
\hline Safety and & SS05 & SS030 0.846 & 0.887 & 0.664 \\
Security & SS02 & 0.816 & & \\
& SS01 & 0.769 & & \\
\hline Stainable Housing & SHD05 & 0.795 & 0.879 & 0.645 \\
Design & SHD04 & 0.799 & & \\
& SHD03 & 0.823 & & \\
SHD02 & 0.801 & & \\
SHD01 & 0.789 & & \\
\hline
\end{tabular}

\section{Discriminant Validity}

The extent to which a construct differs from others is described as discriminant validity. In other words, discriminant validity is required to determine the extent to which comparable notions have distinct values. In terms of latent variables, this type of validity measured responses without cross-loadings (Arbuckle, 2011; Hair et al., 2010; Rasli, 2006). Discriminant validity states that constructs (latent factors) are not significantly related, meaning that they 
may be evaluating the same environment. Discriminant validity may be rejected if the correlation between exogenous constructs is greater than 0.80. (Cooper \& Schindler, 2011; Rasli, 2006). Furthermore, the value of construct-to-construct correlations is greater than the square root of the AVE value, implying discriminant validity. Table 1.2 shows the AMOSgenerated inter-construct correlations.

Table 1.2: $\quad$ Convergent Validity

\begin{tabular}{|l|l|l|l|l|l|l|l|}
\hline & PV & SHD & FS & FLS & RB & FV & SS \\
\hline PV & 0.804 & & & & & & \\
\hline SHD & 0.635 & 0.803 & & & & & \\
\hline FS & 0.432 & 0.642 & 0.773 & & & & \\
\hline FLS & 0.686 & 0.656 & 0.522 & 0.806 & & & \\
\hline RB & 0.609 & 0.723 & 0.651 & 0.548 & 0.790 & & \\
\hline FV & 0.627 & 0.731 & 0.672 & 0.695 & 0.646 & 0.742 & \\
\hline SS & 0.556 & 0.757 & 0.739 & 0.638 & 0.733 & 0.741 & 0.814 \\
\hline
\end{tabular}

Privacy $=$ PV, Stainable Housing Design $=$ SHD, Family Structure $=F S$, Family Life Style $=F L S$, Religion and

Beliefs $=$ RB, Family Values =FV, Safety and Security $=$ SS

Table 1.2 shows the correlation among variables and square root of AVE values. Results revealed that all variables exhibited sufficient discriminant validity which means the listed values of square root of AVE were more than the inter-construct correlation of each variable and inter-construct correlation values were also below 0.80 . Thus, the findings presented adequate proof of constructs' discriminant validity.

\section{Hypotheses Results for Direct Relationships}

Table 1.3 summarizes the outcomes of six hypotheses, as well as statistical values from the SEM analysis, standardized estimate, crucial ratio, and degree of significance are only a few examples (P-value .000) All of these connections and theories have been thoroughly examined in the previous section.

Table 1.3: $\quad$ Summary of Hypotheses Results for Direct Relationships

\begin{tabular}{|l|l|l|l|l|l|l|}
\hline S. No. & Hypothesis & Estimate & S.E. & C.R. & p-value & Results \\
\hline H1 & FS ? SHD & 0.116 & 0.114 & 2.041 & 0.041 & Accepted \\
\hline H2 & FV ? SHD & 0.202 & 0.177 & 2.861 & 0.004 & Accepted \\
\hline H3 & FLS? SHD & 0.134 & 0.134 & 2.340 & 0.019 & Accepted \\
\hline H4 & PV ? SHD & 0.149 & 0.133 & 2.457 & 0.014 & Accepted \\
\hline H5 & RAB ? SHD & 0.285 & 0.261 & 4.448 & $* * *$ & Accepted \\
\hline H6 & SS ? SHD & 0.313 & 0.144 & 2.378 & 0.017 & Accepted \\
\hline
\end{tabular}

\section{Discussions and Findings}

The objective of this research is to scrutinize the links among between the values of society and culture and long-term design of the houses in the Gaza Strip of Palestine. Furthermore, the role of both social and cultural values in understanding sustainable housing design is examined in this research. Furthermore, the current study offers some key recommendations for academic architecture, government, and UNRWA in terms of adopting sustainable housing 
and construction designs in general. The study proposes a total of six (6) hypotheses based on the objectives and research questions

To begin, researchers look into the relationship between societal ideals and sustainable building design in Gaza. H1: Family structure is favorably associated with sustainable housing design, according to the current study. H2: Family values are linked to environmentally friendly housing design. H3: Family lifestyle is beneficially linked to sustainable housing design. Similarly, all three hypotheses are accepted, including $\mathrm{H} 1, \mathrm{H} 2$, and $\mathrm{H} 3$. The findings of $\mathrm{H} 1, \mathrm{H} 2$, and $\mathrm{H} 3$ are similar to those of prior studies, such as Olayiwola (2006), who has looked at the impact of social and physical characteristics of a neighborhood on people's satisfaction levels.

Social variables, rather than environment, construction techniques, or cost, have a bigger impact on home design, according to Ozaki (2002). Furthermore, according to Alahmed (2014), the social preconditions for housing provision and purchase are necessary for longterm housing and, as a result, a livable environment. Second, the links among cultural values and sustainable house design has been investigated in Gaza. Three hypotheses are offered in the current investigation, including $\mathrm{H} 4$ : Environmentally friendly Housing design has a favorable relationship with privacy. As a result, all three hypotheses, $\mathrm{H} 4, \mathrm{H} 5$, and $\mathrm{H} 6$, have been accepted. The findings of $\mathrm{H} 4, \mathrm{H} 5$, and $\mathrm{H} 6$ are consistent with earlier research, for example, Rapoport (1995) claims that his cultural theories are inextricably linked to the home and its surroundings. Building designs are also influenced by cultural aspects, according to him. (Ghaffarian Hoseini et al., 2014) recognizes the "use of space" as one of the most influenced environmental values in building design by social value. A system of values and ideas is learnt and passed down by a group of people: these establish a set of norms and actions that reflect ideals and define a way of life (Jabareen, 2005). Through the process of socialization, cultural norms are passed down from generation to generation (Makinde, 2015).

\section{Conclusion}

Today, one of the major concerns and emerging issues for many developing countries, particularly those that are economically and politically unstable, is sustainable housing design. The major goal of this study is to see how socio-cultural values impact sustainable building design in Gaza. It is proposed that socio-cultural values are major factors of sustainable housing in Gaza based on the findings of this study. Despite tremendous technical and western-style domination in contemporary house structures around the world, these findings show that the Palestinian community is more likely to retain its family history of housing designs and inherited socio-cultural values.

When it comes to designing a house to fulfil present and future needs, it also demonstrates that family structure and religious beliefs dominate the behavioral and attitudinal inclinations in the Gaza Strip. As a result, within a closely related socio-cultural milieu, such inclinations are passed down to subsequent generations. In the establishment of a better environment for the inhabitants, several governmental sectors and policy-makers have paid close attention to sustainable housing design. Smart houses, in the framework of sustainable housing, use technologies and new models to assure comfort and increase the quality of life. Meanwhile, earlier research investigations in the context of home and spacing disregarded the social, cultural, emotional, and religious components. The current study's findings shed a broad light on sustainable housing design and its interconnections with social and cultural value in the context of long-term development. 
This research employs a mixed approach that includes both quantitative and qualitative findings. Quantitative studies show a link between socio-cultural values and environmentally friendly building design. In addition, qualitative data supports quantitative findings, demonstrating three key themes: social values, cultural values, and sustainable housing design. The findings of this study provide a full understanding for policy-making authorities in the Palestinian Territory's housing industry. This research contributes to the understanding of inhabitants' integral socio-cultural values and patterns in relation to the PCBS-estimated housing unit designs (PCBS, 2017).

\section{References}

Alahmed, A. (2014). The Potential of Political Changes in the Information Age: The Political Challenges Sphere of Saudi. Handbook of Research on Political Activism in the Information Age, 37.

Alaghbari, W. (2010). Factors Affecting Construction Costs in Affordable Housing for Lowincome Group in Sana'a, Yemen. Doctoral of Philosophy Thesis, School of Graduate Studies, University Putra Malaysia, UPM Serdang, Selangor.

Almansuri, A. A., Dowdle, D., \& Curwell, S. (2009). Do Courtyard Houses Provide the Ideal Climatic Solution in Hot Climate Regions? Case Study-Tripoli, Libya.

Ammar, S. M. (2014). A Performance Evaluation of the Housing Associations in Gaza-A Case Study-Tel- al Hawa Housing Project. Paper presented at the Fifth International Conference on Engineering and Sustainability.

Ani, A., Mohamed, N., \& Rahman, N. A. (2012). Socio-cultural influences in the Composition of Traditional Malay House Compounds in Rural Melaka. ALAM CIPTA, International Journal of Sustainable Tropical Design Research and Practice, 5(1).

Arbuckle, J. L. (2011). IBM SPSS Amos 20.0 [Computer Program]. New York: IBM.

Asfour, O. S. (2012). Towards An Effective Strategy to Cope with Housing Land Scarcity in the Gaza Strip as A sustainable Development Priority. Habitat International, 36(2), 295-303.

Cooper, D. R., Schindler, P. S., \& Sun, J. (2011). Business Research Methods. 142-155.

Creswell, J. W. (2013). Research Design: Qualitative, Quantitative, and Mixed Methods Approaches. Sage Publications.

Dempsey, N. (2008). Does Quality of the Built Environment Affect Social Cohesion? Proceedings of the Institution of Civil Engineers-Urban Design and Planning, 161(3), 105114.

Duxbury, N. (2007). Culture as A key Dimension of Sustainability: Exploring Concepts, Themes, and Models. http://www. Culture and Communities. ca/resources/publications. html.

Duxbury, N., \& Jeannotte, M. S. (2011). Introduction: Culture and Sustainable Communities. Paper Presented at the Culture and Local Governance.

Edwards, B. (2000). Sustainable Housing: Architecture, Society and Professionalism. Sustainable Housing: Principles and Practice. London: E and F Spoon.

Edwards, N. C., \& Roelofs, S. M. (2006). Sustainability: The Elusive Dimension of International Health Projects. Canadian Journal of Public Health/Revue Canadienne de Sante'e Publique, 45-49.

Francescato, G., Weidemann, S., \& Anderson, J. R. (1987). Residential Satisfaction: Its Uses and limitations in Housing Research. Housing and Neighbourhood: Theoretical and Empirical Contributions, 43-57. Friedman, A. (2005). Homes within Reach: A guide to the Planning, Design, and Construction of Affordable. Homes and Communities: Wiley. 
GhaffarianHoseini, A., Dahlan, N. D., Berardi, U., GhaffarianHoseini, A., \& Makaremi, N. (2013). The Essence of Future Smart Houses: From Embedding ICT to Adapting to Sustainability Principles. Renewable and Sustainable Energy Reviews, 24, 593-607.

Gilkinson, N., \& Sexton, M. (2007). Delivering Sustainable Homes; Meeting Requirements: A research Agenda. Paper Presented at the Proceedings of XXXV IAHS World Congress on Housing Science, Melbourne, Australia.

Greener, S. (2008). Business Research Methods (1st ed.). Ventus Publishing Aps.

Hamed, S. (2003). Capacity Building for Sustainable Development: the Dilemma of Islamization of Environmental Institutions. Islam and Ecology, 403-421.

Horn, L., \& Skomsvold, P. (2011). Community College Student Outcomes: 1994-2009. National Center for Education Statistics.

Ilesanmi, A. O. (2010). Post-occupancy Evaluation and Residents' Satisfaction with Public Housing in Lagos, Nigeria. Journal of Building Appraisal, 6(2), 153-169.

Jabareen, Y. (2005). Culture and Housing Preferences in A developing City. Environment and Behavior, 37(1), 134-146.

Jiboye, D. (2010). Evaluating Users' Household-size and Housing Quality in Osogbo, Nigeria. Ethiopian Journal of Environmental Studies and Management, 3(2).

Kowaltowski, D. C., \& Granja, A. D. (2011). The Concept of Desired Value as a Stimulus for Change in Social Housing in Brazil. Habitat international, 35(3), 435-446.

Krejcie, R. V., \& Morgan, D. W. (1970). Determining Sample Size for Research Activities. Educational and Psychological Measurement, 30(3), 607-610.

Makinde, O. O. (2015). Influences of Socio-cultural Experiences on Residents' Satisfaction in Ikorodu Low- cost Housing Estate, Lagos state. Environment, Development and Sustainability, 17(1), 173-198.

Mills, C., \& Ota, H. (1989). Homeless Women with Minor Children in the Detroit Metropolitan Area. Social Work, 34(6), 485-489.

Olayiwola, L., Adeleye, A., \& Jiboye, A. (2006). Effect of Socio-cultural Factors on Housing Quality in Osogbo, Nigeria. Paper Presented at the International Symposium on Construction in Developing Economies: New issues and challenges. Santiago, Chile. January.

Opoku, R. A., \& Abdul-Muhmin, A. G. (2010). Housing Preferences and Attribute Importance among Low- income Consumers in Saudi Arabia. Habitat International, 34(2), 219-227.

Ozaki, R. (2002). Housing as A reflection of Culture: Privatised Living and Privacy in England and Japan. Housing Studies, 17(2), 209-227.

Palestinian Central Bureau of Statistics (2017). Preliminary Census Results, PHC 2017, Ramallah, Palestine. Rapoport, A. (1969). Housing and Housing Densities in France. Town Planning Review, 39(4), 341.

Rapoport, A. (1995). Indirect Approaches to Environment-behavior Research. A. Rapoport, Thirty-Three Papers in Environment-Behavior Research, Urban International Press, Newcastle, UK, 489-512.

Rasli, A. (2006). Data Analysis and Interpretation-A Handbook for Postgraduate Social Scientists (+ CD). Penerbit UTM.

Salama, A. M. (2006). A lifestyle Theories Approach for Affordable Housing Research in Saudi Arabia. Emirates Journal for Engineering Research, 11(1), 67-76.

Sidawi, B. (2008). Incorporating Lifestyle in the Design of Affordable Housing in Saudi Arabia Kingdom. Emirates Journal for Engineering Research, 13(2), 67-72. 
Tavassoli, G., \& Fathi, S. (2013). Effective Socio-cultural Factors on Sustainable Design of Urban Space. IAU International Journal of Social Sciences, 3(1), 39-51.

Un-Habitat. (2004). The Challenge of Slums: Global Report on Human Settlements 2003. Management of Environmental Quality: An International Journal, 15(3), 337-338.

Varol, C., Ercoskun, O. Y., \& Gurer, N. (2011). Local Participatory Mechanisms and Collective Actions for Sustainable Urban Development in Turkey. Habitat International, 35(1), 916. 